\title{
Educational Path Analysis of College Students' Socialist Core Values under the New Media Environment
}

\author{
Liang Hao \\ Shandong University of Science and Technology \\ Qingdao, China \\ skdhl@126.com
}

\author{
Jun Shang* \\ Shandong University of Science and Technology \\ Qingdao, China \\ mandysj@163.com
}

\begin{abstract}
The new media has a comprehensive and multilevel influence on the formation and development of College Students' values. On the bas is of analyzing the present situation of contemporary college students' values, the positive and negative effects of the new media environment on College Students' education of socialist core values are analyzed, we can continuously improve the pertinence and effectiveness of college students' socialist core values education from the aspects of setting up new ideas, building new platforms, exploring new methods and establishing new mechanisms.
\end{abstract}

Keywords-the new media; socialist core values; college students; educational path

\section{INTRODUCTION}

According to the data of China Internet Information Center (CNNIC) 41st "statistics report on the development of China Internet network", the scale of Chinese netizens had already reached 772 million by December 2017, of which the scale of mobile phone users reached 753 million $^{[1]}$. Among the Internet users, the proportion of Internet users aged 20-29 years old is $30.7 \%$, which accounts for the largest proportion of Internet users, and students are the largest group of Chinese netizens, accounting for $25.1 \%^{[2]}$. So far, the rapid development of new media represented by "microblog" and "WeChat", including micro film, micro novel, micro video, micro public welfare, has greatly changed the main channel of people's information acquisition, but also exert great impacts on college Students' ways of thinking and ways of life, what's more, the ideological and political education of college students is significantly influenced $^{[3,4]}$. Especially in the new era, how to integrate new socialist media values into the entire process of ideological and political education by means of new media has become a new subject for college educators.

\section{THE CURRENT SITUATION OF CHINESE COLLEGE STUDENTS' VALUES}

There is no denying the fact that under the joint efforts of the whole society, especially the hard work of ideological and political education workers, the contemporary ideology of our country is overall good, the mainstream of ideological values is positive, healthy and upward ${ }^{[4]}$. However, it is clear that the formation of college students' values under the current network environment has been severely affected by various aspects, and some bad signs have emerged.

\section{A. Deviation of value orientation and confusion of ideal and belief}

The open, free, pluralistic social environment created by the new media, makes western countries monopolize the Internet information, and transfer the western values and ideology into domestic people by utilizing advanced technology, especially with the economic strength and comprehensive national strength of the world powers in recent years, some false statements that seriously affect our country's stability and indiscriminate attacks on our party's image are even more blatant. Therefore, the enthusiastic college students whose outlook on life and values are not perfect, are vulnerable to the impact of these bad information, leading to the deviation and distortion of political ideology, national consciousness and core values.

\section{B. The serious utilitarianism and the weak sense of responsibility}

The entertainment, popularity and commercial nature the new media embodies have brought convenience as well as physical and mental relaxation to university students. Nevertheless, the circumstance of focusing more on entertainment than knowledge, more on relaxation than responsibility, more on commerce than culture has made the students' abilities of thought judging and culture learning drop a further step. Bringing about that few number of college students make the power, status or even money as their life goal, in which point make their value orientation utilitarian. At the same time, the virtual and anonymous nature of the new media network has greatly released the "individuality and publicity" of college students, meanwhile, the network sense of responsibility and morality is weakening. In real life it turns out to be caring only about their own needs, in other words, ignoring interests of our country, community and others.

\section{The lack of traditional culture and the decline of moral quality}

Traditional culture which inherits Chinese civilization plays the positive role of regulating the interpersonal relationship, strengthening the collective consciousness of the society and 
agglomerating the national strength. However, the serious deficiency of Chinese traditional culture teaching, environment, atmosphere, results in the phenomenon of Chinese moral quality decline, which exhibits in college the loss of honesty and morality, cheating in the exam and fabricating false information; in the society, there appears reduced social morality, behavior in public that is out of order, even fight, theft and other illegal behaviors. The indifference to the traditional culture and the neglect of the humanistic spirit have hindered the healthy growth of the college students as well as the social atmosphere.

\section{THE POSITIVE ROLE THAT THE NEW MEDIA PLAYS DURING SOCIALIST CORE VALUES EDUCATION}

The new media taking advantage of digital transmission form, the interactive mode of transmission, the real-time transmission speed, and the exceptional transmission resource changes the students' way of thinking and behavior, at the same time, provides convenient conditions for colleges promoting college students' socialist core values education ${ }^{[5,6]}$.

\section{A. The interaction and instance of the new media transmission innovates the carrier of the cultivation of socialist core values of college students}

The new media realizes the real two-way interactive communication. As a carrier, it cracks the traditional one-way education which is called "I say you listen, I pour you drink", at the same time, it promote the core values of college students education from plane to stereo, from static to dynamic, from oral implementation to practice. The education method also changes from moralizing to the enlightening, from indoctrination to full penetration. Especially its immediacy, it greatly improves the spread speed of socialist core values, which makes college students have a faster command of it and put it into practice effectively.

\section{B. The content of new media is rich and varied, which vividly explains the connotation of socialist core values}

Compared with the new media such as microblog and WeChat ,the information in the previous media like websites and newspapers is less, "hot spots" and "focus" information update slowly, which is difficult to meet the needs of college students. And huge amounts of information of the new media as well as its geometric diffusion pattern greatly enrich the content of the rich education, innovate in the performance form, and effectively increase the appeal of the education content and influence.

\section{The equality and affinity of the new media discourse has inspired the self-confidence and self-consciousness of college students to practice the core values of socialism}

Nowadays, in the era of self-media, new media has become the origin and fermentation field of campus public opinion. Participation in current affairs discussion, dissemination of information, and appealing for interest are all displayed by the original ecological "micro-language" of college students. And communicating with school leaders, teachers and classmates in the new media platform is not face to face, so fewer false and stiff, more sincerity and communication. College students eager to be understood and respected in the spirit greatly meet the emotional needs, which in turn make them willing to listen, listening to, so as to inspire the self-confidence and consciousness of practicing the socialist core values.

\section{Attention and tracking function of the new media's have improved the pertinence and efficiency of the ideological and political education}

Through "attention", college educators can instantly understand the rich changes of the students' inner thoughts. Through the "tracking", they can instantly grasp a period of thought and behavior changes of college students. According to these phenomena to analysis its development trend and potential impact, not only we can quickly find and fix problems, but also discover new classic fashion in time so as to form a good education atmosphere. Therefore, attention and tracking function of the new media greatly strengthen the "foresight" of college students' core values education, and improve the pertinence and efficiency of the ideological and political education.

\section{THOUGHTS ON THE EDUCATION OF COLLEGE STUDENTS' SOCIALIST CORE VALUES BASED ON NEW MEDIA}

The questions that must be considered at this stage is how to realize the positive and effective communication of socialist core values under the new media environment and how to guide students to firmly establish socialist core values and practice it in daily life $\mathrm{e}^{[7]}$.

\section{A. Innovate value education mode, and set up a new concept of socialist core values education}

1) Multiple education methods are adopted in order to cultivate students' ability to find correct values. Instead of the traditional inculcation and constantly strengthening education method, through heuristic, comparative, interactive, transposition types and other educational methods, all ways to objectively introduce, combine and compare various values to college students are actively adopted, which guide them to find and select the correct values.

2) Strengthen the media literacy of college students' education, and cultivate students' ability to choose the right values. Colleges should set up media literacy courses during correct period, carry out the media knowledge of education, and help college students understand the characteristics of media properties, operation mode, communication theory and operation mechanism, etc. Colleges should strengthen education of students' information dissemination ethics and law, guide and encourage college students to participate in media information dissemination activities, and enhance their understanding of the media and even the correct values in practice. 


\section{B. Strengthen the guidance of public opinion on campus and explore new methods for developing the education of socialist core values}

1) Take the initiative to master public opinion and guide public opinion scientifically and rationally. It is necessary to establish and improve the security warning and response mechanism for campus public opinion, relying on student working cadres and student backbone, campus information and dynamic public opinion canbe acquired in a timely and effective manner, especially for public opinion events that is significant, sensitive, easy to be divergent and confrontational, explaination and guidance in time are quite necessary. For international and national hot and focus issues, we should issue to college students the views of the central spirit, expert analysis and discussion views through various channels, so as to correctly guide college students to look at problems objectively and rationally, and form correct value judgment and choice.

2) Cultivate "public opinion leaders"actively and give full play to the guidance of public opinion. Colleges and universities have to cultivate party and government cadres, experts and the backbone college student groups, unite the people in charge of campus BBS, post bar and other new media platforms, in order to form the campus "public opinion leaders" group. At the same time, colleges should closely cooperate with various departments, provide useful information to them in time, solve the problem of their feedback, and improve the trust of college students, so as to better guide public opinion.

\section{Create preferable campus atmosphere and build a new platform to carry out the socialist core values education}

1) The advantages of traditional media and new media are combined to promote the effective dissemination of socialist core values. The specialized socialist core value propaganda and education website can be set up to maintain the timeliness and authority of information, help college students to make value judgment and choice, meanwhile,and the micro-blog, wechat and other communication platforms can be built, and actively writing or circulating the content full of positive energy can help guide the cultivation of students' correct values. We should try to establish a three-level new media working platform system of university-college-class league to ensure the transmission effect of core values.

2) Change the mode of mainstream media publicity and enhance the acceptance of socialist core values. In the past, traditional mainstream media monopoly information sources by selectively report according to their own needs, "only the good news, not the bad". Nowadays the concept of publicity must be changed, not only to positively propaganda the theories and policies, but also to expose the shortcomings and problems in social life, and take the initiative to "exposur" all kinds of negative news, put forward the solution and enlighten the students to think.

\section{CONCLUSION}

In short, the new media is the carrier of all kinds of information transmission, the place where ideas meet and collide, and the important influencing factors of college students' core values. If we do not occupy this platform, others will do, if excellent ideology and culture can't be enriched, harmful thoughts dross will erode. Therefore, we must make great efforts to propagate and guide, only in this way can help college students get out of value confusion and set up scientific and correct socialist core values.

\section{REFERENCES}

[1] C.X. Shi, "Study on the Influence of Socialist Core Values on College Students in the New Media,” Research Institute of Management Science and Industrial Engineering. Proceedings of 2017 International Conference on Social Sciences, Arts and Humanities(SSAH 2017).

[2] J.Y. Zhang, "The Core Value System of Socialism Leads the Education of College Students' Values," Proceedings of 2015 International Conference on Management Science, Education Technology, Arts, Social Science and Economics (MSETASSE 2015).

[3] X.Z. Zhang, "The Core Value System of Socialism Leads the Education of College Students' Values," Journal of Henan Normal University (Philosophy and Social Sciences Edition), 2015.

[4] W.B. Qian, "The Impact of New Media on the Value Orientation of College Students and Countermeasures,” 2014.

[5] B. Peng and Y.Y. Yang, "On the Impact of Non-Mainstream Culture on College Students' Values,” School Party Building and Ideological Education, 2014.

[6] E.L. Jiang, "The New Media Environment under the Ideological and Political Education of College Students," The Theoretical Front of the University, 2014.

[7] S.L. Liu, "Cultivation of socialist core values of the basic principles," Ideological and theoretical education, 2013. 